\title{
Photonic Implementation of 4-QAM/QPSK Electrical Modulation at Millimeter-Wave Frequency
}

Yu, Xianbin; Jensen, Jesper Bevensee; Tafur Monroy, Idelfonso

\section{Published in:}

Proceedings of the 2008 IEEE International Topical Meeting on Microwave Photonics jointly held with the 2008 Asia-Pacific Micrrowave Photonics

Link to article, DOI:

10.1109/MWP.2008.4666648

Publication date:

2008

Document Version

Publisher's PDF, also known as Version of record

Link back to DTU Orbit

Citation (APA):

Yu, X., Jensen, J. B., \& Tafur Monroy, I. (2008). Photonic Implementation of 4-QAM/QPSK Electrical Modulation at Millimeter-Wave Frequency. In Proceedings of the 2008 IEEE International Topical Meeting on Microwave Photonics jointly held with the 2008 Asia-Pacific Micrrowave Photonics (pp. ThuP-27). IEEE. https://doi.org/10.1109/MWP.2008.4666648

\section{General rights}

Copyright and moral rights for the publications made accessible in the public portal are retained by the authors and/or other copyright owners and it is a condition of accessing publications that users recognise and abide by the legal requirements associated with these rights.

- Users may download and print one copy of any publication from the public portal for the purpose of private study or research.

- You may not further distribute the material or use it for any profit-making activity or commercial gain

- You may freely distribute the URL identifying the publication in the public portal 


\title{
Photonic Implementation of 4-QAM/QPSK Electrical Modulation at Millimeter-Wave Frequency
}

\author{
Xianbin $\mathrm{Yu}$, Jesper Bevensee Jensen, Idelfonso Tafur Monroy \\ DTU Fotonik-Department of Photonics Engineering \\ Technical University of Denmark \\ DK-2800 Kgs. Lyngby, Denmark \\ Email:xyu@com.dtu.dk
}

\begin{abstract}
We propose a photonic method for generating millimeter-wave 4-QAM/QPSK modulated signals. The method is based on optical phase modulation by multilevel electrical signals and optical carrier-suppression. Simulation results are presented for $2.5 \mathrm{Gsymbol} / \mathrm{s}$ 4-QAM and QPSK signals at a $36 \mathrm{GHz}$ carrier. Furthermore, this method can be extended to generate millimeter-wave $m$-PSK signals and can be incorporated into broadband radio-over-fiber systems to support wireless/ wireline converged access network.
\end{abstract}

\section{INTRODUCTION}

The continue demand from end-users for high capacity wireless communication links encourages us to research for techniques to realize high frequency wireless systems carrying high bit rate signals[1]. Conventional signal generation at radio frequencies (RF) requires signal modulation at baseband or intermediate frequency followed by one or more mixing, amplification, and filtering stages for up-conversion to the desired carrier frequency and removal of undesired spectral components. Radio-over-fiber (RoF) system has recently received considerable attention due to its well-know advantages of high bandwidth, low loss, etc. It is foreseen that hybrid optical wireless systems will be used to delivered to the end user both high capacity and flexibility. Therefore, the generation of millimeter-wave (mm-wave) signals for remote signal delivery in wireless and wireline access networks using photonic techniques is highly desired.

Up to date, most efforts in photonic generation of modulated millimeter wave signlas have been focused on the development of broadband all-optical binary phase-shift keying (BPSK) modulation [2-4]. However to enhance the capacity and the spectral efficiency of communications links, it is necessary to be able to implement more complex formats such as quaternary phase-shift keying (QPSK), $m$-PSK and $m$ quadrature amplitude modulation ( $m$-QAM) which are commonly employed in wireless communication systems. In this sense, some approaches have been proposed for photonic generation of vector modulation subcarrier [5-7]. Typically, they are based on the vector summation technique, which consists in achieving the desired carrier phase and amplitude

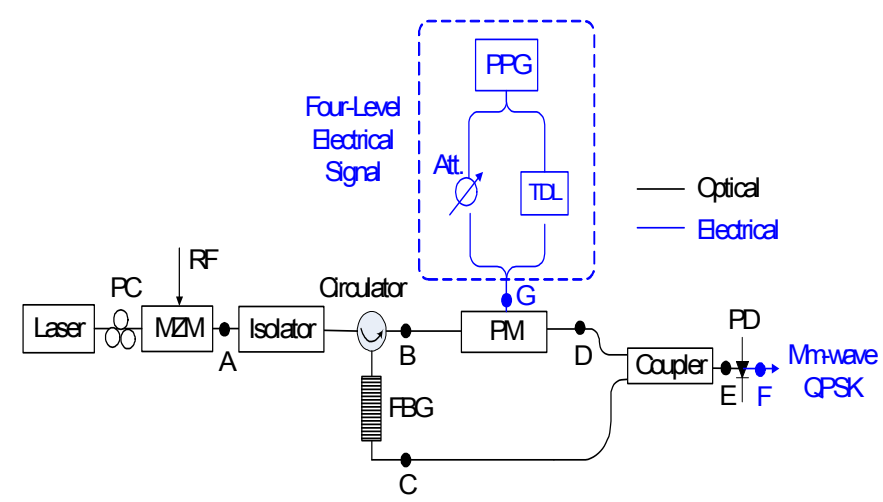

Figure 1 Proposed configuration for photonic generation of millimeter-wave 4-QAM/QPSK. PC: polarization controller, MZM: Mach-Zehnder modulator, PPG: pseudo pattern generator, PM: phase modulator, Att.: tunable attenuator, TDL: tunable delay line, PD: photodetector.

by summing two orthogonal components, namely in-phase (I) and quadrature $(\mathrm{Q})$ components.

In this paper, we propose a photonic method for implementation of millimeter-wave vector modulation formats based on optical phase modulation by using multilevel electrical and optical carrier-suppression.. In this way, the generated high frequency millimeter-wave has narrow linewidth due to the correlated phase noise of the two optical side band used for its generation[8].Proof-of-concept simulation results for $2.5 \mathrm{Gsymbol} / \mathrm{s}$ 4-QAM/QPSK signals at $36 \mathrm{GHz}$ are presented. Furthermore, due to the linearity of optical phase modulators, our proposed method can be extended to implement millimeter-wave $m$-PSK electrical modulation.

\section{OPERATION PRINCIPLE}

The proposed configuration for photonic generation of millimeter-wave 4-QAM/QPSK signals is shown in Figure 1. The continuous wave $(\mathrm{CW})$ from the output of a laser is intensity modulated using a Mach-Zehnder modulator (MZM) which is driven by a radio frequency (RF) signal at frequency 


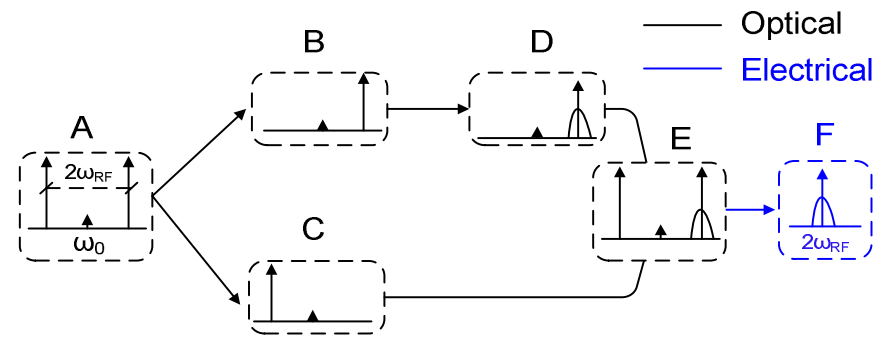

Figure 2 Representation for signal generation at the A-F points shown in Figure 1.

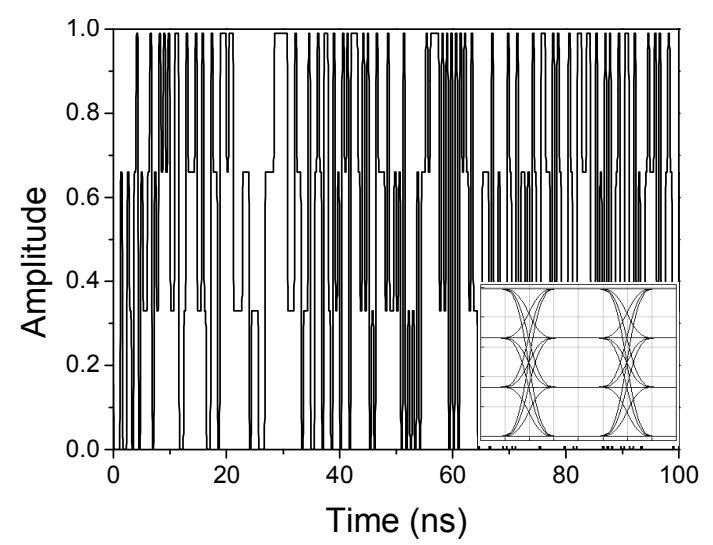

Figure 3 Electrical signals with normalized amplitudelevels of $0,1 / 3,2 / 3$ and 1 at point $G$ of Figure 1 , used to generate 4-QAM modulation. Inset: eye-diagram of four-level signal.

$\omega_{\mathrm{RF}}$. In order to achieve carrier suppression modulation, the MZM is biased at its minimum transmission point. In the optical domain, we can observe two wavelengths with frequency separation of $2 \omega_{\mathrm{RF}}$, as shown in point $\mathrm{A}$ of Figures 1 and 2. These two wavelengths are split by a narrow band fiber Bragg grating (FBG). In this case, as shown in points $\mathrm{B}$ and $\mathrm{C}$ in Figure 1, one wavelength is reflected to the upper optical path and the second is transmitted to the lower optical path. The wavelength in the upper path is phased encoded by a fourlevel electrical signal by an electro-optic phase modulator (PM). The four-level signal can be achieved by using weighted and summing technology. In this way, we apply two different intensity factors to two pseudo pattern generator (PPG) channels ( 1 for $1^{\text {st }}$ channel and 2 for $2^{\text {nd }}$ channel) and sum them. At point $\mathrm{E}$ of the system, these two optical signals are combined in a $3 \mathrm{~dB}$ optical coupler and fed to a high-speed photodetector (PD). QPSK modulated millimeter-wave at frequency of $2 \omega_{\mathrm{RF}}$ is generated by the resulting frequency beating of the two wavelengths as shown at point $F$ in Figures 1 and 2 .

For the reason of simplicity, assuming that the phase deviation between marks and spaces at PM is $2 \pi$, the optical field at the input of $P D$ can be given as:

$$
E_{i n}=\sqrt{P_{1}} \exp j\left[\left(\omega_{0}+\omega_{R F}\right) t+\varphi_{i} \cdot 2 \pi\right]+\sqrt{P_{2}} \exp j\left[\left(\omega_{0}-\omega_{R F}\right) t\right]
$$

Here $\omega_{0}$ is the optical angular frequency of the CW output from laser, $\varphi_{i}(i=0,1,2,3)$ are normalized electrical

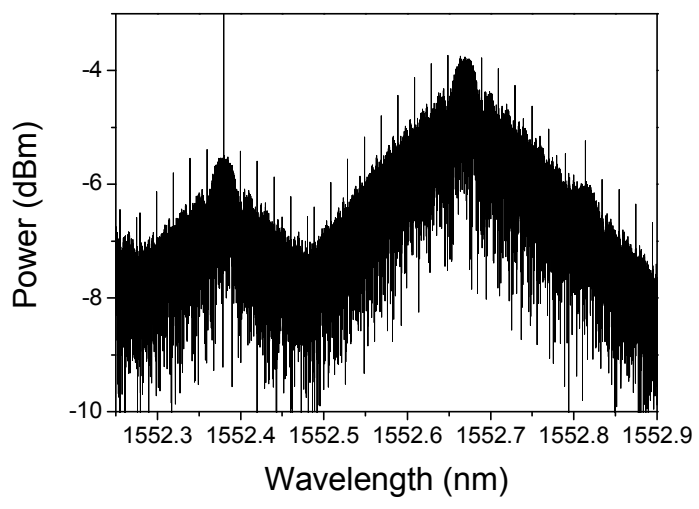

Figure 4 Optical spectrums at the input of PD.

level inputs to PM, respectively. At the output of the PD, the generated electrical signal can be expressed as:

$$
E_{\text {out }} \propto 2 \sqrt{P_{1} P_{2}} \cos \left[2 \omega_{R F} t+\varphi_{i} \cdot 2 \pi\right]
$$

Therefore, when $\varphi_{i}=1 / 8 \cdot 2 i$ and $\varphi_{i}=1 / 8 \cdot(2 i+1)(i=0,1$, 2, 3), 4-QAM and QPSK modulated millimeter-wave is obtained, respectively.

\section{SimULATION RESULTS AND DisCUSSIONS}

In order to test the proposed scheme, a series of computer simulation using VPITransmissionMaker tool are performed. The system simulated follows the configuration shown in Figure 1. An $18 \mathrm{GHz}$ RF modulating frequency and $2.5 \mathrm{Gbps}$ PPG are used. As shown in Figure 3, an electrical signal with normalized amplitude-levels of $0,1 / 3,2 / 3$ and 1 is obtained by controlling the weighting factor and delay time. When the phase deviation is set as $3 \pi / 2$, the generated millimeter-wave will have phase states of $0, \pi / 2, \pi$ and $3 \pi / 2$. The inset indicates the corresponding eye diagram. At the input of the PD, the optical spectrums of the combined optical signals coming from the two optical paths are shown in Figure 4. We can observe that the optical signals at longer wavelength are modulated with digital information. In principle, the second optical signals at shorter wavelength should have no modulation. Due to the limited suppression ratio of FBG, the modulation at shorter wavelength is very weak comparing to that of longer wavelength.

To analyze the generated millimeter-wave 4-QAM, the output optical signals are detected in a high-speed PD and the subcarrier signal is synchronously demodulated using a mixer driven by a local oscillator (LO) which has double frequency of that deployed in the transmitter. A lowpass filter with cutoff frequency of $1.8 \mathrm{GHz}$ is used to remove high frequency components. Figure 5 displays the electrical frequency spectrum at the output of the PD. The demodulated signals can be observed using a sampling scope, and the digital constellation and the demodulated Q-component eye diagram are depicted in Figure 6. By adjusting the phase-shift of the LO to demodulate the different quadrature signals, Figures 


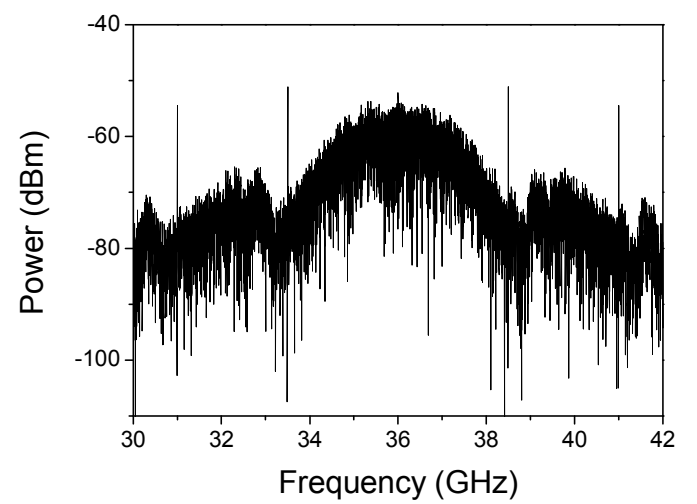

Figure 5 Electrical spectrums at the output of PD.

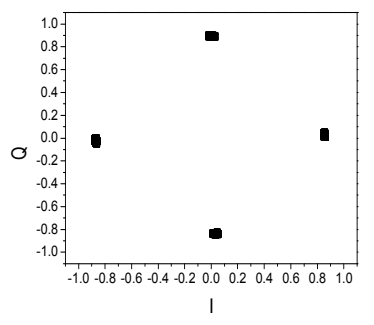

(a)

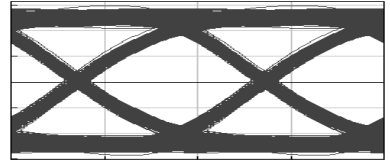

(b)

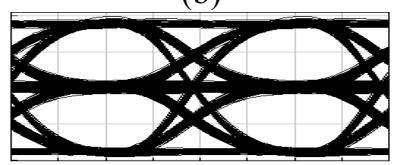

(c)
Figure 6 (a) Constellation of demodulated 4-QAM signals. (b) Eye-diagrams for digital signal when phase shift of LO $\pm 45^{\circ}$, Horizontal scale: $200 \mathrm{ps} / \mathrm{Div}$, Vertical Scale: $50 \mathrm{mv} /$ Div. (c) Eye-diagrams for multilevel signal when phase shift of LO $0^{\circ}$ or $90^{\circ}$. Horizontal scale: 100ps/Div, Vertical Scale: 100mv/Div.

6(b) and 6(c) show the demodulated eye diagrams of the digital and multilevel signals, which are obtained with phase shift in the LO of $\pm 45^{\circ}$ and $0^{\circ} / 90^{\circ}$, respectively. We can notice that a $2.5 \mathrm{Gbps} 4-\mathrm{QAM}$ signal at $36 \mathrm{GHz}$ is successfully generated. Furthermore, the phase error caused by imbalance of two optical paths is less than $1^{\circ}$ in the simulation. For high-frequency millimeter-wave real system, it is possible to compensate for the imbalance by adjusting the LO phase.

As discussed in section, if we apply electrical signal with normalized amplitude-levels of $1 / 8,3 / 8,5 / 8$ and $7 / 8$, and PM phase deviation of $2 \pi$, millimeter-wave QPSK with phase states of $\pi / 4,3 \pi / 4,5 \pi / 4$ and $7 \pi / 4$ will be generated. The demodulated constellation is shown in Figure 7. In principle, this method can be also used to implement millimeter-wave $m$-PSK when by applying $m$-level electrical signals to the phase modulator provided if the level $\varphi_{i}=2 \pi / m \cdot i(i=0,1,2$ ... (m-1)).

\section{CONCLUSIONS}

We propose a photonic method implement the generation of millimeter-wave 4-QAM/QPSK electrical modulation

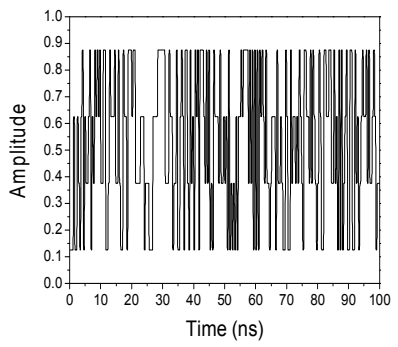

(a)

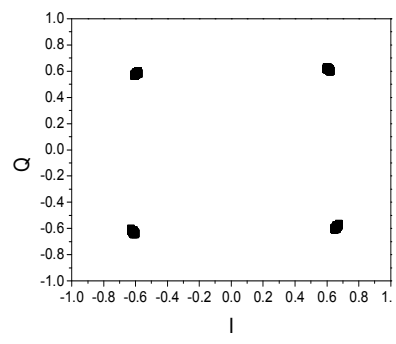

(b)
Figure 7 (a) Electrical signals with normalized amplitude-levels of $1 / 8,3 / 8,5 / 8$ and $7 / 8$ at point $\mathrm{G}$ of Figure 1, used to generate QPSK modulation. (b) Constellation of demodulated millimeter-wave QPSK.

formats. The millimeter-wave is generated by using optical carrier-suppression modulation employing an optical MZI intensity modulator. The 4-QAM/QPSK is imposed by optical phase modulation driven by a four-level electrical signal. We simulated this proposed system showing successful generation for the case of $2.5 \mathrm{Gsymbol} / \mathrm{s}$ 4-QAM/ QPSK signals at $36 \mathrm{GHz}$. This proposed method can also be used to implement generation of millimeter-wave $m$-PSK modulation formats. As this method used conventional photonic components, it has potential applications in broadband RoF systems for wireless/wireline converged access network.

\section{REFERENCES}

[1] K. Ohata, K. Maruhashi, J. Matsuda, M. Ito, W. Domon, and S. Yamazaki, "A 500 Mbps $60 \mathrm{GHz}$-band transceiver for IEEE 1394 wireless home networks," in 30th Eur. Microwave Conf. Proc., vol. 1, Oct. 2000, pp. 289-292.

[2] Y. Doi, et al., "Phase shift keying using optical delay modulation for millimeter-wave fiber-optic radio links", J. Lightwave Technol., 2000, 18, pp. 301-307.

[3] A. Loayssa, and D. Benito, "Dispersion-tolerant all-optical subcarrier modulator for broad-band BPSK transmissions", IEEE Photonics Technol. Lett., 2004, 16, (4), pp. 1161-1163.

[4] A. Martinez, et al., "Experimental demonstration of dispersion-tolerant $155 \mathrm{Mb} / \mathrm{s}$ BPSK data transmission at $40 \mathrm{GHz}$ using an optical coherent harmonic generation technique", IEEE Photonics Technol. Lett., 2003, 15, (5), pp. 772-773.

[5] W. D. Jemison, A. J. Kreuzberger, and E. Funk, "Microwave photonic vector modulator for high-speed wireless digital communications," IEEE Microw. Wireless Compon. Lett., vol. 12, no. 4, pp. 125-127, Apr. 2002.

[6] P. Candelas, J. M. Fuster, J. Martí, and J. C. Roig, "Optically generated electrical-modulation formats in digital-microwave link applications," $J$. Lightw. Technol., vol. 21, no. 2, Feb. 2003, pp. 496-499.

[7] R.Sambaraju, M.A. Piqueras, V.Polo, J.L. Corral, J. Marti, "Generation of Multi-Gigabit-per-Second MQAM/MPSK-Modulated MillimeterWave Carriers Employing Photonic Vector Modulator Techniques", $J$. Lightw. Technol., vol. 21, no. 2, Feb. 2003, pp. 3350-3357.

[8] X. Yu, X. Zheng, H. Zhang, "Polarization state rotation filter for optical generation of continuously tunable millimeter-wave signal employing an external intensity modulator", Optical Fiber Technology, vol. 13, no. 1, 2007, pp. 56-61. 